\title{
Study of Feminism Society
}

\author{
Fangping Cheng ${ }^{1}$ \\ ${ }^{1}$ Yancheng Institute of Industry Technology, Yancheng, 224001 \\ 346591653@163.com
}

KEYWORDS: Feminism Society; Human History; Sexual Study

\begin{abstract}
Feminism is a full range of social science research practice, which emphasizes the value of subjectivity and personal experience, both seek ways to work in the traditional disciplines, and aims to break these traditional knowledge revolutions and such a study the nature defines its diversity of methods. It is an absorbent formed traditional discipline and method, confrontation relation Amendment and innovation. Features feminist social science research is to determine the method of selection factors, while the use of research methods and is a concrete manifestation of these features.
\end{abstract}

\section{Introduction}

Penetration and expansion of feminist thinking is that since the 1960s the Western intellectual, one can not ignore the cultural phenomenon. As the social and political basis, this trend in contemporary with western feminist movement while roots in the soil of Western counterculture. Its influence is not reflected in the change of centuries accustomed to gender issues and gender perspective, but also in a new look at the historical, social, cultural and even knowledge of traditional gender perspective appears. In academia, the direct result is to facilitate the formation of a new interdisciplinary research fields and methods, which is women's studies (women 's studies) or called feminist studies (feminist studies) as well as the rise of gender analysis (gender analysis ) appears methods. The main women's studies is academic feminism (academic feminism). Early research topics mainly related to the situation of women in oppression and root cause analysis of gender inequality, and then no longer limited to issues of concern to women or gender, but turned to the Western model the entire academic tradition and knowledge to re-examine, and then attempt Feminism build their own knowledge patterns and academic traditions. Gender analysis of women's studies as a basis, mainly from a basic concept of feminism on gender issues: the sex (gender) is a cultural construction and social institutions, between gender (sex) it is not a purely physiological sense there is no necessary correlation. Gender Culture represents the patriarchal ideology, and thus penetration among all the concepts, systems and behaviors, become a point of Western civilization and constitute knowledge building. Therefore, a new perspective of gender analysis is an indispensable social research.

\section{The Main Method of Feminist Social Science}

Feminist interview study "Use of semi-structured interviews have become feminists seeking to acquire their main way to explain the active participation of the respondents regarding the data aspects of their lives." (Quoted in Reinharz, 18) semi-structured and non-structured interviews is a kind of qualitative data collection techniques, it is different from ethnographic research interviews, 
investigators need long-term involvement of the respondents live, it is also different from investigation or structured interviews, unstructured interviews because researchers and respondents interact freely in the state, inclusive of the opportunity to explain and discuss, while investigation is typically exclude such opportunity. Open-ended interview study exploring perceptions of reality, so that researchers form theory, which in this way complements the emphasis quantitative, less trying to validate some of the assumptions of the closed-end interview study. Open interviews study provides a number of non-standard information, except that the researchers understand the differences between people, but also can cause researchers to hear people in their own language express their views, thoughts and memories, which is to women's studies is particularly important, because it is a way to understand women, breaking the centuries completely ignored women's perspectives, or endorsement by men for women the situation. Interviews conducted research on the control concept also avoids the development associated with the people and consistent with the interests of women to others. Feminist scholars interview method applied to a wide variety of research projects, the subject matter relates to housework, mothers, religious experience, experience of violence, sexual abuse and sexual harassment, as well as on abortion and reproductive child's personal decision, and so on.

Contemporary ethnographic field work or study belong multivariate methods, which typically include observation, participation, file analysis and interviews, and thus combine the strengths and weaknesses of each approach. In the field of academic feminism into the initial stage of feminist criticism pointed positivist approach in a way that distorted male-centered knowledge, for this reason, they believe, or positivist method of choice, especially open-ended interviews and ethnography Feminist should have a place in the social sciences. The emphasis on the interpretation method you choose depends on the investigator to go deep into the social environment, the aim of understanding and knowledge of both researchers and study between subjects. Researchers from the point of view of feminism, feminist ethnography has three main purposes, first, the documentary depicts the life and activities of women, who opened the blindfold was formed by traditional male-centered, so that the viewer participation women as full members of the community to look at. Second, from the perspective of their own understanding of these women, from their own viewpoint to understand the experiences of women bias correction of the main non-feminist participatory observation, namely that the women's activities and thoughts are trivial and shallow, from a society of men standpoint to describe women. The third purpose is to recognize the social context of women, feminist anthropologist tries to women is described as a social background dictates, rather than from the background or in anatomy, personality and social class basis up to explain women. Although feminist ethnography in research to determine the purposes, observation method and background with the traditional method of different ethnic history and improved, but they still face a number of contradictions in the following aspects. First, although women scholars have tried to study the position of women from women, but these women are not always trust them, especially when social class, race, ethnicity or sexual preference a difference. If women scholars failed to win the trust of the women she studied as a researcher and feminist, she will have a double feeling of failure. The second contradiction is common in participatory observation, that is close by researchers still maintain a certain distance in order to adhere to the independent status of objectivity and researchers, to which the majority of feminist researchers have advocated approaching women are aware of their prerequisites. The third point relates entirely contradictory and full participant observer between this role, many feminist researchers had discussed the importance of combining their own work ethics and epistemology in, as well as shortening the subject and object The importance of the distance between, they believe in participant observation, 
based on the knowledge gained will be due entirely immersed in the study of social and supplemented and strengthened.

\section{Criticism of Mainstream Social Science in Male Supremacy}

Feminism is a major contribution to the social sciences through the traditional mode of social science criticism to complete. Feminism believes mainstream social science norms by male pattern creation and provision of its research in all aspects and objects, themes and content, methods and conclusions of view, are in line with the value system of male-centered, therefore patriarchy It formed a coalition between internal culture. It is too much emphasis on areas and issues of concern to men, neglect and exclusion of women's experiences and feelings, so that women and women in the world become a social science invisible, unseen things. While for social phenomena and human behavior analysis and interpretation, standing on the position of men, from the maintenance of existing social order, power system and mainstream male population interest starting social sciences in general, without regard women as feel marginalized groups and judgment, thus filled with male hegemony. In the social sciences, women as well as women-related issues are usually excluded, or to be derogatory, women experience invisible, Marginalization is a universal phenomenon. Since social action is divided into public and private spheres, and the former is defined as male range of activities, which is defined as the scope of activities of women, and therefore the field of social sciences in public with men linked to the orthodox research, ignore Social life and women linked to the so-called private sphere. Sociologist stressed the official, public actors and actions, and the equally important private, supportive, informal structures and social exclusion of action research, but these tend to be the most frequent areas of women participation. "As a result, in the social sciences, we have not only failed to fully investigate the activities of women, and even distort a woman's activity, and can not understand how the social system is actually run, because we do not have to process one of its most basic, namely exist in informal, explanatory framework and formal, official social structure interaction between this factor into account "(Millman \& Kanter, 1987, p.32).

Feminist thought, although men and women living in the same material world, but the social world in which they live is different. Social requirements, and men and women feel about men and women for life are not the same, such as the social division of labor system will be open to men and women occupational segregation, family life but also to arrange the different roles of men and women and so on. In this sense, men and women are not equal participants in this society, because of gender as an important variable played a key role in the regulation and social sciences tend to ignore it, to find the probability sample study of men pushed to all, ignore the vital areas of women and issues (Abbott \& Wallace, 1996). For example, the definition of "work", often limited to paid work in male-dominated job market, and predominantly female housework neither pay, it is not the column "work" in. The woman in the family as a lot of unpaid work done by housewives, are considered a woman's "vocation" without intervene, therefore, rarely become formal disciplinary research topics of sociology and economics.

Feminist thought, social science Women and female experience of intangible, not a simple oversight on the subjects and themes, but because of the social sciences point of view is androcentric from the value orientation. Social science research in the public domain and the private sphere, reason and emotion, men and women is a gender-based division of metaphor (sexual met-taphor) corresponding ideology, which contains the patriarchal hierarchy of values, profound cultural foundations. This dichotomy of gender ideology and importance of the provisions of the innate differences between men and women, it will create a social and cultural gender attributed to 
biological differences between men and women, thus establishing the gender system, the role of division of labor, gender identity, etc. the rationality of existence, provides a defense for men in patriarchal society dominance and oppression and subordination of women in the family and society. In this sense, the male hegemony in the social sciences is consistent with the social life and social structure of the male hegemony. • feminist sociologist Dorothy Smith (Dorothy Smith) believes that the reason why sociology ignoring a woman and a woman's experience, it is because women are seen as emotional, irrational, a woman's experience is considered subjective, unreal, and therefore can not constitute a basis of knowledge. Sociology of knowledge must be based on the so-called universal experience of men on, its outline is precisely the man in the eyes of the world were distorted world. Therefore, between experience and study women from starting their own lives and feelings found conceptual and theoretical framework of this world experience available there is a serious separation (Smith, 1987). Meanwhile, the experience between two worlds and two men and a woman constitute knowledge which does not have the same status as men construct the world for a woman living in the world who has some authority role, it constitutes the social rule-based relations. "Those subject to the system so that the social structure of sociology dominated by men, that is, those that make a woman trapped in an oppressed situation regime.

\section{Conclusion}

Feminism attacked mainstream male hegemony in the social sciences, critical social research methods and popular value-free methodology advocated, and blamed patriarchal culture dichotomy implied epistemological pattern, trying to construct a female experience-based social research model feminism mainstream social sciences formed a strong impact, but gender differences and cultural exaggeration of knowledge-based constructivist model, making feminism ultimately can not wound the essence of this doctrine and relativism cycle. However, it is envisioned that people no longer on the relationship between knowledge, between the blind to gender and power, which will probably become a reasonable basis for the continued existence of feminist social research and considerable development.

\section{REFERENCE:}

[1] Harding, Sandra. The Science Question in Feminism, Cornist University Press.

[2] Harding, Sandra. Introduction: Is There A Feminist Method? In Feminism and Methodology: Social Science Issues, Ed. By Sandra Harding, Indiana University Press.

[3] Millman, Marcia \& Kanter, Rosabeth M. Introduction to Another Voice: Feminist Perspective Son Social Life and Social Science in Feminism and Methodology, Ed. By Sandra Harding, Indiana University Press.

[4] .Oakley, Ann, Interviewing Women: A Contradiction in Terms, in Doing Feminist Research, Ed. By H. Roberts, London: Routledge \&Kegan Paul.

[5] Reinharz, Shulamit. Feminist Methods in Social Research, Oxford University Press. 